\title{
COOPERATIVISMO DE VIVIENDA POR AYUDA MUTUA FORMACIÓN, EXPERIENCIA Y LUCHA EN URUGUAY
}

\section{Gustavo Javier Machado Macellaro}

\section{Resumen}

Las cooperativas de vivienda, con más de 50 años de historia, han sido una respuesta efectiva para más de 38.000 familias que sienten hacia ellas pertenencia y apropiación. Las cooperativas de ayuda mutua de usuarios están agrupadas en la Federación Uruguaya de Cooperativas de Vivienda por Ayuda Mutua (FUCVAM), que es uno de los movimientos sociales más importantes del Uruguay en la actualidad. La formación es un aspecto que ha ocupado un lugar relevante en las cooperativas, con discontinuidades $y$ tensiones diversas. El artículo analiza las tensiones planteadas entre el saber técnico y el militante, entre la formación política y la técnica (gestión), y aborda tanto los efectos formativos de la organización y la movilización como los dispositivos convocados con dichos fines. En particular, se destacan los momentos de lucha, fundamentalmente de resistencia a la dictadura, como espacios de formación y socialización política.

Palabras clave: formación, cooperativismo de vivienda, experiencia.

\section{Abstract}

Housing cooperativism for mutual help. Education, experience and fight in Uruguay

Housing cooperatives have been an effective response, with 50 years of history, for more than 38,000 families, towards which they feel belonging and appropriation. The cooperatives of mutual help of users are grouped in the Uruguayan Federation of Cooperatives of Housing by Mutual Help (FUCVAM), which is one of the most important social movements of Uruguay at present. Training has occupied a relevant place in the organization, with diverse discontinuities and tensions. The article analyzes these tensions raised between technical and militant knowledge, between political and technical education (management) and the formative effects of the organization and mobilization and the devices convened for such purposes. In particular, the moments of fight, fundamentally of resistance to dictatorship, as spaces for training and political socialization.

Keywords: training, housing cooperativism, experience.

Gustavo Javier Machado Macellaro: Doctor en Educación (Universidad Nacional de Entre Ríos], magíster en Servicio Social (Universidade Federal do Rio de Janeiro-Universidad de la República) y asistente social universitario (Facultad de Ciencias Sociales-Universidad de la República). Profesor adjunto del Departamento de Trabajo Social de la Facultad de Ciencias Sociales de la Universidad de la República.

ORCID iD: 0000-0002-3000-5895

Email: gustavo.machado@cienciassociales.edu.uy

Recibido: 15 de febrero de 2020

Aprobado: 15 de junio de 2020 


\section{Introducción}

El artículo reconstruye la relación de la Federación Uruguaya de Cooperativas de Vivienda por Ayuda Mutua (FUCVAM) con la educación desde una perspectiva histórica y crítica.

FUCVAM es uno de los movimientos sociales más importantes del Uruguay y entendemos relevante la exploración de sus prácticas políticopedagógicas como parte del dossier que integra este artículo. En este marco, el trabajo se propone analizar, con una perspectiva histórica y en diálogo con los distintos contextos de su desarrollo, cómo es desafiada la práctica político-gremial de sostener, defender y consolidar la experiencia cooperativa de miles de familias que autoconstruyen sus viviendas y organizaciones en forma colectiva, en las que las prácticas educativas son un componente insoslayable.

La educación es entendida en sentido amplio, no solo como capacitación o restringida a las instancias convocadas con fines pedagógicos, sino a todos los procesos y actividades que forman a los sujetos participantes. Esto permite pensar los procesos formativos más allá de los dispositivos específicos, para ubicar la praxis sociopolítica como educativa y reconocer el carácter pedagógico de las propias organizaciones populares.

\section{Antecedentes: educación y movimientos sociales}

La relación de la educación con los procesos colectivos y los movimientos sociales es reciente, no obstante, existió una producción previa e importante en los ochenta, con las salidas de las dictaduras en América Latina, fundamentalmente vinculada a la educación popular, donde encontramos la producción agrupada en la Red Alforja y en el Centro de Educación de Adultos de América Latina (CEAAL).

En diálogo con esa producción, están los trabajos de José Luis Rebellato (2000, 1993), basados en la educación popular articulada con la ética de la liberación, que aportan la dimensión ética a la corriente pedagógica latinoamericana en forma orgánica con los sectores que sufren opresiones y explotación.

Otro autor uruguayo de repercusiones y producciones regionales es Raúl Zibechi (2018, 2011, 1999), con publicaciones sobre los procesos formativos en las organizaciones trabajadoras, el movimiento zapatista y 
otras experiencias populares diseminadas en Latinoamérica en defensa de los recursos naturales y la construcción de lo común. Su producción ha aportado a significar el territorio como locus privilegiado de resistencia y de transformación social en clave emancipatoria.

Se destacan también los estudios de Roseli Salete Caldart (2011), integrante del equipo central de educación del Movimiento de los Trabajadores Rurales Sin Tierra (MST), y de Norma Michi y su equipo (2013, 2010; Michi, Di Matteo y Vila, 2012) en Argentina, que profundizan acerca del aporte del materialismo cultural y la educación popular latinoamericana.

Dichas investigaciones toman las categorías experiencia - del historiador inglés Edward P. Thompson- y estructura de sentir - de Raymond Williams - como aportes relevantes para pensar los procesos populares de formación.

Otros estudios a considerar son los realizados sobre movimientos sociales urbanos, en los que tienen centralidad la lucha por el derecho a la educación y la instauración de espacios alternativos, como los bachilleratos populares. En estas investigaciones podemos encontrar a Elisalde, Ampudia (2009), Sirvent (2009) y a Gentili y Sverslick (2008) en la región.

En estas producciones aparece con vigor el papel de la organización popular como fuente y espacio de educación, así como las disputas entre movimientos sociales y Estado por construir los sentidos y prácticas de la educación.

Otro grupo importante es el de los trabajos que se vinculan a empresas recuperadas, procesos asociativos, y autogestionarios, entre los que destacan los de los uruguayos Gerardo Sarachu (2009) y Anabel Rieiro (2010), y los de la argentina Ana Inés Heras Monner Sans (2011), en los que la categoría autogestión tiene relevancia para los procesos formativos y como anticipo de formas organizativas poscapitalistas.

Es destacado el trabajo de Pablo Imen sobre educación cooperativa, fundamentalmente en su libro Una pedagogía para la solidaridad. Aportes del cooperativismo de crédito, de 2012, en el que distingue diferentes perspectivas educativas a las que llama pedagogía de la tradición (buceo por la historia del movimiento y de los pioneros del cooperativismo mundial), pedagogía de la realidad (recorrido por la historia y la coyuntura), pedagogías de la praxis (como unidad de reflexión y acción) y, por último, distingue lo que denomina pedagogías intencionales específicas (temas de gestión propiamente).

Todos ellos dan un marco conceptual y metodológico para pensar las diferentes estrategias de formación que ha desarrollado el movimiento cooperativo.

Además de los mencionados, destacamos a María da Gloria Gohn(1992), de Brasil, que aporta una visión sobre movimientos sociales y educación en el campo de la hegemonía, y otros trabajos compilados por Roberto Elisalde 
(2009). También se desarrolló una investigación en la Facultad de Ciencias Sociales de la Universidad de la República (UDELAR), no publicada, por un equipo coordinado por Alejandro Casas y Alfredo Falero (2011).

Los antecedentes citados permiten pensar la educación más allá de los dispositivos creados con esos fines, para ubicar la praxis social como pedagógica en la construcción de alternativas y el carácter pedagógico de los propios movimientos.

En las producciones reconocidas y estudiadas vinculadas a la educación en procesos de acción colectiva, se podrían tomar diferentes espaciosmomentos de formación que Michi, Di Matteo y Vila identifican en los movimientos populares: a) "como actividad específica de formación dentro de un movimiento", b) "como actividad compartida con otras organizaciones populares", c) "dentro de espacios de deliberación y decisión", d) "en el marco de acciones de protesta", e) "como parte de iniciativas de acercamiento a personas y comunidades que no participan de la organización" (2012, pp. 34-35).

Los espacios-momentos, como los definen estos autores, permiten visualizar que no solo se entiende la formación en los dispositivos o la institucionalidad creados en ese sentido, sino también en la construcción cultural de la organización y la producción de subjetividades de los participantes en las experiencias colectivas, donde el movimiento es un espacio educativo en sí.

FUCVAM y las cooperativas de ayuda mutua, que cuentan con un alto reconocimiento - sobre todo internacional — han sido poco estudiadas desde los espacios académicos, y todavía menos su vínculo con la educación y los procesos formativos.

\section{Aspectos metodológicos}

El artículo indaga históricamente la relación de FUCVAM con la educación, identificando las prácticas político-gremiales, las concepciones de educación y los dispositivos formativos que dialogan y disputan con el contexto y desarrollo del propio sistema cooperativo.

Se establecieron cuatro períodos históricos, que están definidos por los cambios del contexto sociopolítico, en los que la política pública de vivienda -en particular, hacia las cooperativas - tuvo efectos directos: a) de las experiencias iniciales hasta el advenimiento de la dictadura (1966-1973), b) el proceso de la dictadura cívico-militar (1973-1984), c) la restauración democrática y el período neoliberal (1985-2004) y d) los gobiernos progresistas (2005-2019).

La información producida para el presente artículo es resultado de una exhaustiva revisión bibliográfica y documental (periódicos y publicaciones de FUCVAM, de diversos Institutos de Asistencia Técnica [IAT], de 
cooperativas, prensa, reglamentos, discursos, planes de formación, actas de asamblea e informes de la Agencia Nacional de Vivienda [ANV]).

Fue muy importante para la recuperación histórica un conjunto de publicaciones del Centro Cooperativista Uruguayo (CCU), en formato de revista, con cometidos de información, formación y difusión de experiencias: Cuadernos Cooperativos Uruguayos (décadas del sesenta y setenta), Vivienda (década del ochenta) y Dinámica Cooperativa (desde la década de los ochenta hasta la actualidad). En este mismo sentido encontramos publicaciones de la organización no gubernamental Foro Juvenil (década del ochenta), además de revistas sociales de FUCVAM $(1980,1990,1995)$ y El Solidario, su publicación regular oficial.

Por otro lado, se recuperan entrevistas individuales y grupales realizadas a cooperativistas, a exdirigentes de FUCVAM y a integrantes de los dispositivos de formación de la Federación en el proceso de investigación realizado por el autor en su estudio de doctorado sobre los aprendizajes en los procesos colectivos en las cooperativas de vivienda (Machado, 2017).

\section{Las cooperativas de vivienda en Uruguay}

Las cooperativas de vivienda surgen en 1966 a partir de grupos autogestionarios en el interior del país, apoyados por un centro de promoción y asesoramiento al cooperativismo, el CCU, con gran protagonismo en el desarrollo cooperativo nacional hasta nuestros días.

Las primeras experiencias influyeron en la inclusión del capítulo de cooperativas en la Ley n. ${ }^{\circ} 13.728$ (denominada Plan Nacional de Vivienda), aprobada en diciembre de 1968, que constituye el impulso por el que se formaron y crecieron las cooperativas.

Los estudios sobre el origen del cooperativismo de vivienda (Midaglia, 1992; Nahoum, 2008; González, 2013) analizan que fueron vertientes del sistema cooperativo, por un lado, la práctica de la autoconstrucción en la población uruguaya $\mathrm{y}$, por otro, las organizaciones sindicales, de las que surgieron las primeras cooperativas. Estas últimas dieron una fisonomía particular y fortaleza al movimiento.

Las cooperativas se constituyen con base en dos sistemas: el de ahorro previo y el de ayuda mutua. En ambos el grupo tiene que aportar al menos un $15 \%$ del valor de las viviendas; en el primero, con un ahorro grupal anterior a la adjudicación de las viviendas y en la ayuda mutua, aportando su mano de obra en el momento de la construcción.

A su vez, se dividen en dos regímenes de propiedad: el de usuarios y el de propietarios. Explicado sintéticamente, el de usuarios implica que la propiedad es colectiva e indivisa y cada socio obtiene uso y goce de la vivienda. El de propietarios se regula por la legislación de propiedad horizontal y cada socio tiene libre disposición del inmueble. 
La ayuda mutua como proceso comunitario de autoconstrucción, además de configurar una forma de aportar valor para la construcción de las viviendas, supone un rol central en el control colectivo y la apropiación de la experiencia. Es el trabajo colectivo y comunitario en la construcción de la totalidad de las viviendas, sin conocer hasta el final cuál será la de cada socio, una de las expresiones más importantes de la experiencia cooperativa uruguaya.

La ayuda mutua ha sido incorporada en otros programas de vivienda, con resultados positivos en su mayoría, pero no asociada a la autogestión y participación en todo el proceso como ocurre en las cooperativas de vivienda, lo que termina reduciendo su potencialidad exclusivamente en los efectos sobre el valor, abaratando los costos por la mano de obra gratuita que aportan los participantes.

En las cooperativas, en cambio, se da lo que Pelli define como autoconstrucción con autogestión:

"[...] que los habitantes desarrollen y ejerciten roles y actitudes sociales, en el curso de la construcción de su vivienda, que difieran y superen el rol que les es habitual, de subordinación a los actores con mayor poder (económico, político, intelectual, social, ritual).” (2001, p. 9).

Con relación a la participación, la estructura organizativa de las cooperativas posibilita la participación de sus socios no solo en la fase de construcción de las viviendas, sino también en la gestión anterior y posterior a la obra.

El financiamiento de los diferentes grupos cooperativos está a cargo del Ministerio de Vivienda, Ordenamiento Territorial y Medio Ambiente (MVOTMA) y se gestiona por medio de la ANV.

La cooperativa se conforma como empresa constructora asumiendo, en forma autogestionaria, todas las responsabilidades funcionales y legales que le competen a una organización privada. En este caso, se organiza como una administración colectiva, democrática y participativa que se queda con el producto de su construcción, a diferencia de las demás empresas constructoras, que lo realizan por encargo o para la venta de lo producido.

Este proceso definido como autogestión es otra de las particularidades y supone la asunción de las decisiones y responsabilidades en todo el proceso. Es la expresión máxima de la autonomía, no en un concepto liberal, ya que el Estado financia las viviendas, sino por la gestión de la totalidad de las decisiones por parte del grupo, tanto las económicas como las políticas y vinculadas al proyecto social, urbano y arquitectónico. 
La expresión de autonomía (y autogestión) no supone una experiencia aislada, como sostiene Rebellato:

"[...] no significa independencia total, sino protagonismo, constitución de sujetos, en dependencia con el entorno y el mundo. A la vez, la autonomía no puede pensarse como una situación en soledad, sino como condición humana necesariamente intersubjetiva. Las subjetividades se constituyen en el diálogo con los demás. Lo que, asimismo, requiere redescubrir la autenticidad como exigencia del reconocimiento de la propia identidad y de la identidad de los demás." (1997, p. 37).

Para efectivizar la autogestión, asistir y formar en dicho proceso, la Ley n. ${ }^{\circ} 13.728$ también crea los IAT, que son equipos multidisciplinarios que apoyan a la cooperativa en la adquisición e implementación del crédito y son corresponsables del proyecto habitacional.

Es así que los grupos optimizan su autogestión, consolidando complejos habitacionales de gran calidad arquitectónica y urbanística con menores costos, como surge claramente de los estudios realizados en distintas épocas (Terra, 1986; Abbadie et al., 2016) y de los valores de tasación actual de los distintos programas del MVOTMA (s. f.).

A los efectos de evitar la especulación sobre las viviendas, la ley también prevé que, para su venta en las cooperativas de usuarios, el socio debe renunciar a la cooperativa que le reintegra lo que aportó en trabajo o ahorro y amortización del préstamo. Este hecho permite un énfasis en el grupo con la elección del nuevo asociado, un freno a la especulación sobre una línea de crédito de interés social y una forma de control social del grupo sobre la mercantilización del bien.

Un elemento destacable en los complejos cooperativos es la calidad de las construcciones, que permite integrarse al entorno barrial con una propuesta estética adecuada. No obstante, muchas veces el diseño no continúa el trazo urbano de la zona y tiene mayoritariamente un desarrollo hacia adentro. Algo similar sucede con el uso de los salones comunales o servicios incorporados por las cooperativas, que obtienen una fuerte identidad cooperativa, aunque no barrial más amplia.

En el Censo Nacional de 2011 se registraron 30.045 hogares en cooperativas de vivienda, que representan el 2,62\% del total de los hogares del país. El aumento mayor se dio en la última década (2011-2019) y actualmente hay más de 38.000 viviendas (ANV, 2020). 


\section{Gráfico 1. Obras cooperativas por año de inicio}

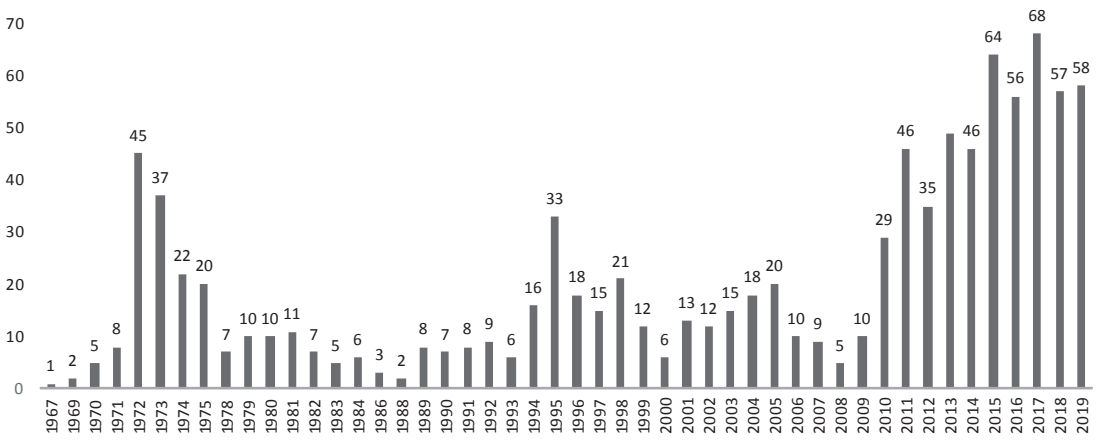

Fuente: Elaboración propia a partir de datos del INE (2010) y la ANV (2020).

Si bien 2017 fue el año con mayor inicio de obras cooperativas, al tener la reglamentación vigente un tope de 50 viviendas por cooperativa, el número mayor de viviendas en obra corresponde a 1973. A fines de ese año, existían 43 cooperativas construidas o en obra, que totalizaban 3.342 viviendas (Terra, 1986, p. 59), mientras que, en la actualidad, las 43 cooperativas de construcción o inicio de obra más reciente suman 1.262 viviendas (ANV, 2020).

\section{Organización cooperativa y educación}

El movimiento cooperativo internacional y nacional reconoce la necesidad de formar en valores y prácticas distintas de las dominantes, que promuevan y fomenten la cooperación. La educación es uno de sus principios fundamentales.

Entendemos los procesos educativos en múltiples escenarios y actividades, en tanto los grupos se forman en la propia experiencia de organización, lucha y gestión, en el encuentro con otros - pares o técnicos$y$ en instancias convocadas con esos fines.

En la perspectiva asumida la formación es un proceso vinculado con las experiencias sociales de los colectivos y los sujetos, y por ello distinguiremos, con fines descriptivos y analíticos, por un lado, instancias, momentos y prácticas que constituyen a los sujetos y los forman y, por otro lado, instancias convocadas y espacios con objetivos de formación y capacitación.

La dialéctica de experiencia y conciencia, tomada de Thompson (1981), posibilita pensar las acciones colectivas como experiencias educativas para los participantes. En ellas la formación es un proceso de socialización política, que se produce a través de objetivos, principios, estructura y tareas mediante los cuales las organizaciones explicitan ciertas finalidades educativas, no exentas de contradicciones. 
Caldart (2001) advierte que tornar consciente este proceso y contribuir a la reflexión sobre él es una de las grandes tareas pedagógicas y abona una corriente teórica que entiende que los movimientos sociales y las prácticas colectivas constituyen en sí mismos un principio educativo.

Esta perspectiva representa una forma de concebir política y pedagógicamente la experiencia, y, en tal sentido, comprender y llevar a cabo acciones formativas. Tal concepción es resultado de un esfuerzo por dilucidar la relación entre la experiencia y la subjetividad (Di Matteo, Michi y Vila, 2012, p. 92).

Los autores sostienen que la producción de subjetividad en las acciones colectivas es favorecida en momentos de fermento de la lucha social o en la constitución de proyectos políticos, más o menos organizados en torno a valores, ideas y demandas, que recuperan historias comunes y tradiciones, lo que la ubica en el campo cultural, generando para los participantes redes, lazos sociales, círculos de interacción y formación donde enraizarse.

Dice Simone Weil que el enraizamiento es una de las necesidades del ser humano. Tener raíz implica participar activamente de una colectividad que conserva vivos determinados "tesoros del pasado" y cierto "presentimiento del futuro" (Caldart, 2011, p. 23).

La acción colectiva más o menos organizada en movimientos sociales, al accionar en el campo público o común, inclusive en el acontecer interno, grupal, supone una producción simbólica al implicar valores sociales que muchas veces cuestionan los dominantes. Pero también la producción simbólica se vincula a la construcción de identidad relacionada con emblemas, hechos, historia común, con la misma construcción de una mística compartida, definida por Caldart "como sentimiento materializado en símbolos que ayudan a las personas a mantener la utopía colectiva", donde "raíz y proyecto se constituyen de valores" (2011, p. 24), y estos son motores de la movilización y cohesión colectiva. Michi (2010) señala que se enlaza con los valores, la tradición y los símbolos que los contienen y supone un elemento que se materializa en prácticas culturales y cotidianas, como formas de lucha, determinados emblemas y acciones en actividades, himnos, consignas y pertenencias colectivas. La mística, así, tiene un potencial reproductivo de las organizaciones, a la vez que cohesiona.

Lo colectivo, como espacio de resonancia de la voz y la acción, supone aprendizajes alimentados por la diversidad y la sinergia que imprime si esta es reconocida.

La alteridad se construye en el diálogo como posibilidad de interlocución, forma de expresión de la diferencia y de lo común por venir, con las tensiones que ello implica. El aprendizaje de lo común, en tanto las matrices culturales han sido permeadas por el individualismo y la racionalidad instrumental, supone una tensión, un movimiento en lo conocido, por tanto, es un desafío insoslayable su potenciación en las prácticas pedagógicas con dichos objetivos. 
Los aprendizajes en espacios colectivos, donde se cohabita, suponen diálogo y crítica, y eventualmente un proceso de transformación de lo propio y de lo ajeno (Tapia, 1997).

En la búsqueda de identificar los aprendizajes que se producen en los procesos colectivos, es importante atender a la relación entre el proceso de construcción de la organización y la producción de subjetividades en estos procesos y su relación.

Michi, Di Matteo y Vila afirman:

“[...] los miramos desde una perspectiva pedagógica, por dos razones: la producción de la organización y su cultura tiene efectos formativos sobre las personas y además en los mismos movimientos, pueden (y con frecuencia, suelen) pensarse desde una reflexión pedagógica en el sentido de producir y potenciar esos efectos formativos. Pensar pedagógicamente las experiencias (como prácticas significadas) que atraviesan los participantes de movimientos populares, nos lleva a sostener que no puede distanciarse la visión de lo que sucede en los momentos educativos sistemáticos, como un curso de formación o una escuela propia de una organización, de la dinámica cultural del movimiento.” (2012, p. 25).

Thompson plantea que el origen de la experiencia de las personas resulta de condiciones independientes de su voluntad y no se convierten por reflejo en conciencia social.

Esta concepción amplía la visión de experiencia como empiria, lo sucedido como simple existencia, evidenciando su base materialista, donde la experiencia forma a las personas, proponiendo una relación dialéctica entre experiencia y educación, fundamentalmente en la perspectiva de formar la conciencia de clase.

La experiencia es entendida como huella que deja el ser social en la conciencia social (Thompson, 1981). Se distancia, también, de la visión popular en la cual la experiencia implica un cuerpo consolidado de conocimientos a través de una práctica consuetudinaria, que muchas veces es un obstáculo conservador para el aprendizaje. La experiencia supone, en la perspectiva de Thompson, la posibilidad de incorporar lo nuevo a partir de experimentar lo que le acontece al sujeto. ${ }^{1}$

Michi, Di Matteo y Vila colocan tres cuestiones que son centrales para analizar los procesos colectivos con relación a la acción educativa: a) el papel de las relaciones microsociales, intersubjetivas, y su valor político; b) lo "prefigurativo", referido a alternativas, horizontes o proyectos políticos; y por último c) el papel de la subjetividad y el sujeto (2012, p. 28).

1 "La experiencia surge espontáneamente en el ser social, pero no surge sin pensamiento; surge porque los hombres y las mujeres (y no solo los filósofos) son racionales y piensan acerca de lo que les ocurre a ellos y a su mundo." (Thompson, 1981, p. 21). 
Sobre el primer punto, la alteridad supone siempre encuentro/ enfrentamiento con otra subjetividad, por tanto, es el primer punto de negociación, diálogo y síntesis de saberes. El proceso de organización posibilita a los sujetos adquirir habilidades de comunicación, negociación y lucha como necesidad de este proceso, en el que la articulación entre pasado, experiencia y visión de futuro puede imprimir en los sujetos horizontes, sentidos y orientación como anticipación, lo que conforma la noción de proyecto, prefiguración (Ouviña, 2012) o factualización de alternativas (Tapia, 2008), como gérmenes o posibilidades de establecer otras relaciones sociales desde ya.

Las prácticas de las organizaciones que pujan por instaurar sentidos contrahegemónicos son espacios y momentos privilegiados para la formación, en tanto experiencias que confrontan valores y explicitan orientaciones de la sociedad.

Zemelman y León (1997) plantean la tríada memoria, experiencia y utopía, como los elementos constitutivos de la subjetividad que vinculan el pasado con el presente como experiencia sedimentada en significados y sentidos, en tanto apropiación del mundo, y al presente con el futuro, como horizontes de sentido posibles.

Tomar esta tríada como el núcleo constituyente de la subjetividad tiene un valor heurístico y hermenéutico para comprender la confluencia de estos distintos planos de la apropiación de la realidad por parte de los sujetos sociales. En este sentido, formar parte de una cooperativa y formarse son procesos que no se preceden ni se desencadenan, sino que están dialécticamente articulados en la experiencia.

La organización, como uno de los momentos o espacios de la formación, no solo configura modos de hacer, decidir y pertenecer, sino que también contiene lo grupal y lo colectivo como espacios de encuentro, intercambio y negociación de ideas, valores y visiones sobre los hechos y procesos.

La cooperativa implica construcción, organización y convivencia como espacios de expresión de lo grupal y colectivo donde se confrontan y visualizan, con mayor fuerza y cotidianeidad a la vez, formas de hacer y estar en el mundo y con los otros.

\section{FUCVAM, las luchas y la formación}

FUCVAM es uno de los movimientos sociales de mayor relevancia en la actualidad. En sus 50 años desarrolló, fundamentalmente durante la dictadura militar, un papel protagónico en la articulación y la defensa del movimiento popular uruguayo.

FUCVAM agremia a las cooperativas de usuarios de ayuda mutua y es la única organización con la magnitud y la presencia pública antes mencionadas. 
$\mathrm{Su}$ trayectoria, reconocida a nivel nacional e internacional, ${ }^{2}$ la coloca como una organización que ha contribuido al desarrollo de experiencias cooperativas y sostenido su desarrollo.

Nuclea actualmente a 453 cooperativas habitadas (18.288 viviendas), 52 en obra (1.508 viviendas) y 122 en trámite del préstamo (2.932 familias) (FUCVAM, s. f.). Tiene una estructura permanente similar a la de las cooperativas, con alcance nacional.

El proceso de desarrollo de FUCVAM es analizado sintéticamente en cuatro períodos, así como los elementos de coyuntura que impactaron en él, para indagar sobre las acciones educativas que sostuvo en su trayectoria.

\section{Las experiencias fundadoras [1966-1973]}

A partir de la incorporación del sistema cooperativo en la Ley n. ${ }^{\circ} 13.728$, los grupos, vinculados fundamentalmente a trabajadores sindicalizados, comenzaron a multiplicarse a un ritmo importante en todo el territorio nacional.

El 24 de mayo de 1970 las tres cooperativas pioneras del interior del país, junto a otras ocho que surgieron a partir de la ley, se reunieron en la inauguración de la primera de ellas, en Isla Mala, Florida, para fundar la Federación Uruguaya de Cooperativas de Ayuda Mutua. ${ }^{3}$

Su creación apareció como una necesidad de las cooperativas iniciales para articular información y trámites entre las del interior y las capitalinas. Surgió en un momento de gran conflictividad social por las luchas de los sectores de trabajadores, la guerrilla urbana y la unificación de la izquierda en una expresión política - el Frente Amplio - como respuesta a necesidades vinculadas con la concreción de las primeras experiencias.

La Federación fue tomando cuerpo y desarrollo por la acción permanente de las cooperativas, que crecían a gran ritmo. Hasta 1973 trabajó con relativo éxito en la conquista de terrenos, la aceleración de la gestión de los préstamos y las obras (FUCVAM, 1995, p. 3). Tuvo un papel importante en la promoción de nuevos grupos y en favorecer la comunicación dentro del movimiento y con las diferentes autoridades públicas.

El CCU jugó un papel muy importante, no solo en la promoción de grupos, sino también en la conformación de la propia federación, asesorando y

2 La experiencia cooperativa de FUCVAM ha sido promovida en diversos países de América y obtuvo la mención de honor a la trayectoria en defensa del derecho a la vivienda, otorgada por el Comité de Hábitat de las Naciones Unidas en 2007. En 2012 el Habitat Award al mejor esfuerzo de transferencia de experiencia solidaria en materia de vivienda.

3 Es relevante destacar que el estatuto fundacional de FUCVAM, en las disposiciones transitorias, fija en su artículo 61: "Desígnese un Consejo Directivo provisorio integrado por: COVIMT, COVINE, COVIAFE, CONSTRUIR Y COVIGRAMA". Lo mismo ocurre cuando se designa la Comisión Fiscal (Municipales de Paysandú, COSVAM y 25 de Mayo). Es decir, la representación en los órganos de dirección de la nueva federación era asumida por las personas, pero en nombre de sus cooperativas o matrices. 
generando los primeros cursos sobre cooperativismo. Hasta los años ochenta, FUCVAM no había desarrollado espacios educativos propios, eran los IAT los que cumplían ese rol en la formación de los cooperativistas, "antes los espacios de formación eran fundamentalmente por los IAT, en FUCVAM no se había instrumentado" (cooperativista, citado en Menéndez, 2014, p. 40).

\section{La dictadura y la resistencia [1973-1985]}

Con el advenimiento de la dictadura militar, el 27 de junio de 1973, a la represión al movimiento popular uruguayo se sumaron, en el caso de las cooperativas, medidas de desarticulación y enlentecimiento de los trámites que inhibieron su desarrollo cuantitativo.

Como parte de la desarticulación del movimiento popular un número importante de cooperativistas estaban sujetos a controles, proscripciones o detenciones. No obstante, las cooperativas mantuvieron su vida interna y la resistencia a la dictadura, ya que, por ley, tienen que reunir a sus asambleas -muchas decisiones tienen que contar con su aprobación-, consejos directivos y otras comisiones, mientras que en la sociedad en general eran prohibidas otras formas de reunión. Las reuniones también se improvisaban en las obras o en festejos.

Por tanto, las cooperativas mantenían cierto accionar colectivo que permitió albergar a diferentes demandas y actores sociales y políticos, generando espacios importantes de socialización política y cultural, que convirtieron a las cooperativas en ámbitos significativos de resistencia del movimiento popular.

En este sentido, "es particularmente señalable que en un momento donde las agrupaciones colectivas son proscritas, FUCVAM emerge como actor social, promovido por una política pública" (Midaglia, 1992, p. 83) y combatido a la vez.

La oclusión de la actividad sociopolítica y el enlentecimiento cuantitativo permitieron el desarrollo en FUCVAM de un área de servicios: Central de Suministros (compra colectiva de materiales de obra) y Planta de Prefabricados (elaboración de elementos constructivos con tecnología que facilitaba la ayuda mutua y abarataba costos), así como servicios sociales y culturales en las cooperativas mediante un convenio con la Asociación Cristiana de Jóvenes (ACJ). ${ }^{4}$

Al finalizar este convenio, además del impacto en lo organizativo y social en las cooperativas participantes, quedaron formados grupos de teatro, murgas y artesanos que, en el contexto del combate a la dictadura, encontraron canales de expresión y desarrollo.

4 Asociación Cristiana de Jóvenes, organización referente que cuenta con importantes instalaciones deportivas y desarrolla, además, acciones educativas y de promoción social. 
Fue en los grandes conjuntos cooperativos e intercooperativos, como las mesas y zonas, donde se dio la mayor cantidad de servicios complementarios a las viviendas: policlínicas, bibliotecas, centros educativos, cooperativas de consumo o almacenes comunitarios, centros deportivos y culturales con muchas actividades en los salones comunales y gran participación social.

El movimiento cooperativo se consolidará fuertemente en el terreno cualitativo, constituyéndose en una de las pocas experiencias que, durante la etapa de dictadura, mantendrá instancias de encuentro y socialización autónoma de importantes grupos de trabajadores impedidos de organizarse legalmente en el terreno sindical. El cooperativismo de vivienda ha sido, dicho en pocas palabras, una gran escuela de participación popular en la construcción de viviendas, lógicamente, pero también en la administración autosustentada de servicios sociales tales como policlínicas, guarderías, comedores, bibliotecas, etc. (Rodríguez, 1985: p. 210).

A partir de la década del ochenta FUCVAM, junto a las nuevas formas del movimiento sindical —Plenario Intersindical de Trabajadores (PIT) el estudiantil - Asociación Social y Cultural de Estudiantes de la Educación Pública (ASCEEP) - y organizaciones de derechos humanos, concertaron acciones autónomas en la denominada Intersocial. Luego, junto a los partidos políticos, lograron ir abriendo camino a la democracia a partir de la Intersectorial.

En 1983 se produjo un fuerte enfrentamiento entre FUCVAM y el Banco Hipotecario del Uruguay (BHU) por la negativa de la Federación a pagar un reajuste de las cuotas de amortización impuesto en forma ilegal. Ante esto, como medida de lucha, las cooperativas resolvieron continuar pagando el valor anterior e iniciar una huelga de pagos del aumento. Esta medida colocó a dicha organización como el primer actor social capaz de contestar o desestimar una decisión gubernamental durante el período dictatorial (Midaglia, 1992, p. 99).

Así, FUCVAM se presentó como un actor fuerte y unido, lideró las demandas por vivienda y concitó amplios apoyos, en la medida que canalizó la disconformidad de la población con la dictadura y sus acciones políticas y económicas.

Frente a esta lucha, el Consejo de Estado aprobó el Decreto-ley n. ${ }^{\circ} 15.501$, que determinaba el pasaje a propiedad horizontal de las cooperativas en régimen de usuario, para así limitar al movimiento cooperativo, transformando a sus integrantes en propietarios y anulando su capacidad de acción colectiva.

FUCVAM, ante la sanción de esa normativa, recurrió a diversas formas de protesta: presentó un recurso de inconstitucionalidad ante la Suprema Corte de Justicia y promovió la recolección de firmas para realizar un referéndum que la derogara.

En contextos de restricción de la democracia representativa y de persecución política a los oponentes al régimen cívico-militar, se recurrió a 
un mecanismo de democracia directa, lo que muestra la audacia de la medida y la incertidumbre acerca de si los ciudadanos registrarían su firma, como producto del miedo impuesto por el terrorismo de Estado.

La posición asumida por la Federación de recurrir a mecanismos de protesta propios de un sistema democrático y, a la vez, utilizar el marco institucional otorgado por la ley en su carácter de cliente colectivo de una agencia estatal, ponía de manifiesto no solo la naturaleza política del enfrentamiento, sino también la potencialidad conflictiva de este sector (Midaglia, 1992, p. 101).

Las demostraciones de apoyo fueron muy amplias: el primer día de recolección (26 de febrero de 1984) se alcanzaron las 300.000 firmas, superando en 90 días las firmas necesarias. No obstante, el gobierno desconoció esta expresión popular y no dio lugar al recurso.

Se observa, entonces, cómo los espacios de participación generados en la transición del régimen autoritario fueron "aprovechados" por esa organización para concretar una real presencia en el medio y obtener apoyos políticos y ciudadanos capaces de asegurar la legitimidad de sus reclamos.

En los últimos años de la dictadura militar los salones comunales de las cooperativas fueron espacios de resistencia democrática, donde se manifestaron expresiones sociales, políticas y culturales que evadían la censura dictatorial y promovían nuevas formas de acción colectiva y cultural.

\section{Acciones educativas del período}

La Federación no integró en su primera década espacios de formación en sentido estricto - ello era cubierto por los institutos- pero estos fueron promovidos como uno de los componentes del convenio con la ACJ (1976-1982).

En 1981 asumió una nueva Comisión de Fomento en FUCVAM, que estimuló la sistematización de las experiencias de las cooperativas y un primer curso de capacitación, intensivo, pago por los cooperativistas participantes, organizado por unidades temáticas: la problemática de la vivienda en el Uruguay y la solución cooperativa, el marco jurídico, la administración de las cooperativas (organización), elementos de programación, contabilidad y función del tesorero, la organización de servicios (fondos sociales, consumo, educación, salud, recreación). Evidencia contenidos políticos en formatos técnico-instrumentales.

En 1982, la XVIII Asamblea Nacional de FUCVAM aprobó por unanimidad una propuesta de una de las cooperativas de Mesa 4 (COVIMT 6), que planteaba encarar:

"[...] un estudio para encauzar el tema de la educación cooperativa y capacitación de técnicas cooperativistas, en análisis conjunto con otros sectores cooperativos, con el fin de promover la institucionalización de 
programas educativos, considerando incluso la participación oficial en el tema." (FUCVAM, 1990, p. 19).

Con dicha resolución, en 1983, se imprimió el Cuaderno de Formación $n .^{\circ} 1$, con el contenido de la Unidad Temática 1 desarrollada en 1981 y luego se creó el Centro de Formación Cooperativa (CFC), reconociendo la necesidad "de una acción permanente de educación, encuadrada políticamente dentro de sus objetivos y estrategia y coherente en su enfoque metodológicos con los principios de participación y autogestión que sustenta: la educación para a ser una tarea política del Movimiento" (FUCVAM, 1990, p. 19).

Reconociendo que no se agota en él la formación del movimiento, el nuevo CFC establece entre sus objetivos: "Contribuir a la formación de dirigentes cooperativistas eficaces y comprometidos con el desarrollo del Movimiento" y "Contribuir a que el barrio cooperativo se convierta en una experiencia de vida comunitaria y no en un mero barrio dormitorio sin vida propia" (FUCVAM, 1984).

El CFC se integró con tres cooperativistas mujeres, del campo de la educación, con el apoyo de dos asistentes sociales del Departamento de Educación del $\mathrm{CCU}$, a quienes se sumaron otros técnicos para charlas específicas, todos en forma militante.

En esas primeras etapas no existía un modelo acabado de formación, se establecían ciclos con cursos básicos para las diferentes etapas (cooperativas en trámite, en obra y habitadas), cursos medios (dirigentes de cooperativas) y superiores (cuadros del movimiento), en el esquema que venía realizando el CCU con las cooperativas asesoradas, cuyos técnicos eran los encargados de este, junto a dirigentes.

A la vez, se realizaron paneles y charlas sobre temas de reflexión y lucha de la Federación: "Situación de la vivienda en Uruguay", "La vivienda y sus prolongaciones dentro del conjunto cooperativo" y "Salario y vivienda".

\section{Democracia, neoliberalismo y lucha [1985-2004]}

La situación conflictiva entre FUCVAM y el BHU se mantuvo. La derogación del Decreto-ley n. ${ }^{\circ} 15.501$, tan debatida y peleada, se produjo a nivel parlamentario recién a fines de 1986, luego de la declaración de su inconstitucionalidad por parte de la Suprema Corte de Justicia.

Conjuntamente con la derogación, se exigió que las cooperativas ratificaran la voluntad de continuar siendo usuarios, por voto secreto. Las cooperativas en sus asambleas ratificaron la decisión y solo una de FUCVAM no mantuvo dicha condición, ubicada en uno de los barrios de mayor aumento de valor del suelo (exdirigente de FUCVAM, citado en Machado, 2017, p. 152).

No obstante, el movimiento cooperativo continuaba con grandes obstáculos para su crecimiento cuantitativo, que arrastraba desde la dictadura, 
como fueron las autorizaciones para nuevas personerías jurídicas, el acceso a las tierras (condición para solicitar el crédito) y los préstamos.

En 1989, varias cooperativas de FUCVAM ocuparon terrenos ociosos de la Intendencia de Montevideo y luego, en 1992, un terreno de la Facultad de Agronomía de la UDELAR, reivindicando así la creación de carteras de tierras oficiales para las cooperativas.

En 1990, el mapa político se modificó, no solo por la asunción del Partido Nacional al gobierno, sino por la experiencia inédita del triunfo de la izquierda en el gobierno departamental de la capital.

Las autoridades municipales firmaron un convenio de tierras con FUCVAM por el que adjudicaron diez predios para cooperativas, dando respuesta a una vieja reivindicación de la Federación e iniciando un convenio de transferencia de terrenos de la cartera de tierras departamental.

En 1990 se creó el MVOTMA, con una orientación al mercado e incluido en la estrategia de reforma del Estado (achicamiento), lo que no mudó la política habitacional ni la relación con FUCVAM.

La contemplación de las cooperativas de vivienda en los planes quinquenales de vivienda fue marginal, si bien la movilización de FUCVAM logró modificar los montos propuestos, fundamentalmente en el último gobierno del siglo XX.

En la década de los noventa, a partir de la agudización de la problemática urbana y la experiencia y sensibilización que provocó la ocupación de tierras, FUCVAM tomó la bandera de la reforma urbana, sumando intereses excluidos anteriormente, como los de los sectores de extrema pobreza y la reivindicación de las áreas centrales de la ciudad.

En 1992, el movimiento cooperativo probó ser una alternativa apropiada de solución a la problemática de vivienda de los sectores más desfavorecidos. Fue a partir de la cooperativa COVIITU 78 (20 familias desalojadas de un exhotel de la Ciudad Vieja) que, con los mismos costos de un programa de núcleos básicos evolutivos, se construyeron cooperativas que superaban el doble del metraje edificado con mejor calidad constructiva y organización colectiva.

Esto provocó una fuerte discusión interna en la Federación por las modificaciones que implicaba integrar sectores de extrema pobreza con otros formatos de vivienda y formas organizativas diferentes.

La otra línea de la propuesta de reforma urbana fue exigir la utilización de espacios centrales de la ciudad para cooperativas, iniciando reciclajes con buenos resultados, a partir primero del financiamiento de la Intendencia de Montevideo y luego del MVOTMA.

Fue una época de movilizaciones y obras en ejecución hasta la grave crisis de 2002, cuando se recortaron préstamos y se enlentecieron las partidas por avances de obra.

FUCVAM desarrolló proyectos sociales en las cooperativas, financiados por la cooperación internacional (Maestro de la Comunidad, Salud 
Comunitaria, Plan Alimentario), además de grandes movilizaciones, entre ellas, marchas a pie desde el interior a Montevideo, cuyo punto culminante fue la marcha a Punta del Este en 2003.

\section{Acciones educativas del período}

En 1986 se realizó una sistematización y evaluación con los participantes de los primeros tres años del CFC de FUCVAM y se concluyó que "la formación más rica es la que surge del quehacer diario, la que surge de nuestra acción organizada y solidaria para el logro de nuestros objetivos comunes" (FUCVAM, 1990, p. 20).

Allí se abandonó la realización de cursos centralmente para trabajar con las cooperativas, desde sus propios problemas, adoptando la metodología de la educación popular, promoviendo diagnósticos participativos, trabajando con los grupos para identificar sus necesidades educativas y realizando talleres en las cooperativas y acompañamiento de las experiencias organizativas (FUCVAM, 1987).

En el marco de esta incorporación y diálogo con el enfoque de la educación popular, se articuló con las organizaciones nacionales y regionales vinculadas a dicha propuesta político-pedagógica. ${ }^{5}$

En 1985, con apoyo del Centro Cooperativo Sueco, se comenzó a trabajar para la fundación de la Confederación Uruguaya de Entidades Cooperativas (CUDECOOP) como organización de tercer grado, lo que permitiría financiar proyectos en algunas de las federaciones vinculadas a la formación cooperativa y el desarrollo institucional (exintegrante del CFC de FUCVAM, citado en Machado, 2017, p. 199).

El primer proyecto financiado integró un programa de formación de educadores cooperativistas, un programa de acompañamiento y desarrollo de las cooperativas habitadas, un programa de trabajo con jóvenes, un programa para cooperativas en formación y trámite, y un programa de capacitación y desarrollo del propio CFC de FUCVAM (FUCVAM, 1987).

$\mathrm{Al}$ inicio de la década de los noventa, el CFC se encontró consolidado $\mathrm{y}$ con funcionamiento activo, con subcentros en Montevideo y en el interior. Contar con el apoyo económico internacional le permitió tener cooperativistas rentados, un equipo de militantes, hacer pequeñas publicaciones y sostener importantes intercambios con redes del país y la región. Participó de la fundación del Comité de Educación de CUDECOOP y se vinculó a la Asociación Latinoamericana de Centros de Educación Cooperativos (ALCECOOP) y al CEAAL. Ambos vínculos fortalecieron su institucionalización.

5 Una de las trabajadoras sociales del CCU, Arlés Caruso, estaba vinculada al CEAAL y a la educación popular. 
La Federación se encontraba movilizada por las ocupaciones de tierras y procesando un conjunto de debates, lo que constituyó un campo fértil para acciones educativas, todo lo cual no inhibió un fuerte debate sobre el lugar del CFC y la orientación política de la Dirección Nacional, que llevó a cuestionar si el lugar de la formación no era la lucha y tarea de los dirigentes, "esa fue la gran brecha" (exintegrante del CFC de FUCVAM, citado en Machado, 2017, p. 201).

En 1992, el CFC dio un giro y generó una síntesis entre las posiciones en debate anteriores. Además de cambiar la coordinación, promovió nuevas orientaciones en su propuesta educativa, que tuvo continuidades y rupturas con su proceso anterior.

Entendemos que todos los procesos de organización social contienen una dimensión educativa, aun cuando no se explicita su intencionalidad. En las prácticas cooperativas existen, al igual que en otras organizaciones populares, "situaciones" colectivas de aprendizaje y crecimiento a partir de las necesidades de dar respuesta a los problemas que en forma cotidiana estas organizaciones deben enfrentar para sobrevivir o desarrollarse. La propia práctica social de la organización genera "situaciones educativas" que pueden ser aprovechadas para desarrollar un programa de formación y capacitación (FUCVAM, 1992).

Esta etapa se caracterizó por acompañar la formación en el proceso organizativo y de lucha del movimiento:

“[...] el instrumento educativo volvió a tensarse, de una etapa digamos de movilización y contención de los grupos, la gente se mantuviera aferrada a la expectativa, pasamos a una cuestión como de reelaboración política, hubo una ideologización muy fuerte del movimiento, por un lado la discusión, toma de tierra como movimiento de lucha, eso generó un debate muy fuerte, la franja uno, la organización política de los sectores más vulnerables, el sector informal de la economía informal organizada en cooperativas, que generó un debate muy fuerte, muy duro, la reforma urbana, que plantea la ciudad como escenario político, las áreas centrales como nueva demanda para las cooperativas, genera un momento de mucho debate." (exintegrante del CFC, citado en Machado, 2017, p. 201).

Cuando se retomaron los préstamos, surgieron necesidades de formación específicas de los grupos, por ello, el CFC implementó un conjunto de cursos regulares de gestión cooperativa que luego repitió todos los años.

La Escuela Nacional de Formación Política, que funciona como un programa dentro del CFC, realiza cursos sobre problemáticas coyunturales y temáticas centrales. En estos cursos participan militantes de FUCVAM, estudiantes universitarios y militantes sociales de otras organizaciones. 
En 1997, el CFC creó, dentro de su estructura de programas, la Cátedra Tota Quinteros, ${ }^{6}$ que funcionó hasta el año 2006 y realizó actividades sobre derechos humanos, coyuntura nacional e internacional.

Otro hecho importante de este período fue, en 1999, la aprobación de la Declaración de Principios de FUCVAM, documento que, aunque breve, es la síntesis de un proceso de discusión e intercambio con los cooperativistas de todo el país.

Desde una perspectiva "clasista y plural", como lo define el propio documento, afirma:

"Se da fundamental importancia a la formación y capacitación cooperativa de sus socios. La formación que emerge del análisis de la propia práctica, es la que mantiene en definitiva sin desviaciones de ningún tipo los principios y fundamentos que son la base de sustentación ideológica del proyecto. La formación debe ser descentralizada y orientada a todos los sectores del Movimiento Cooperativo, así también en los distintos niveles de trabajo no solo en instancias centrales, sino también debe trabajarse en la propia práctica de la cooperativa, buscando rescatar de lo cotidiano una experiencia superadora. La Cooperativa, concebida como empresa, debe ser potenciada en su máximo grado, logrando que cada uno de los socios a partir de su propia experiencia vital sea capaz de generar una propuesta removedora y replicable, capaz de ser desarrollada en todo el Movimiento Cooperativo. Los instrumentos formativos deben ser representados en forma permanente, y deben estar instalados en la discusión colectiva del Movimiento a los efectos de lograr que toda la masa social tenga acceso a esa capacitación y a la transmisión de experiencias realizadas." (FUCVAM, 2000, p. 4).

Era una época de exigencias de las obras, de la crisis económica de 2002 y de mucha movilización. FUCVAM unificó la acción educativa con los programas sociales que desarrolló en las cooperativas, además de las grandes movilizaciones, en una coordinación entre el CFC y la Comisión de Desarrollo Social.

Muchos de los nuevos dirigentes de FUCVAM del final de este período e inicio del siguiente se formaron en el programa Escuela de Formación Política del CFC y contribuyeron a la renovación generacional de los cuadros del propio movimiento.

\section{El escenario de los gobiernos progresistas [2005-2019)}

En esta coyuntura, FUCVAM, como todo el movimiento popular, tuvo tensiones y contradicciones que fueron configurando momentos de mayor en-

6 Luchadora social, exedil, madre de Elena Quinteros (desaparecida en 1976 por la dictadura militar). Durante sus últimos años vivió en la cooperativa COVITEA. 
frentamiento, fundamentalmente por expectativas incumplidas (mayor asignación presupuestal para el financiamiento, intereses financieros de los préstamos, acceso a tierras), lo que llevó a la Federación a tensiones a su interna entre estrategias de negociación y de lucha confrontativa.

"Fue un momento de bastante confusión, lo veías en las bases, el discurso era: yo remé tanto para poner este gobierno que yo no lo voy a atacar. Había un discurso de que no había plata para préstamos." (exdirigente de FUCVAM, citado en Menéndez, 2014, p. 70).

Paralelamente, quienes integraron el Plan Social Alimentario, con otros militantes, se sumaron en la cogestión de programas sociales entre la Federación y el Ministerio de Desarrollo Social, particularmente en los programas Uruguay Trabaja (trabajo protegido) y Rutas de Salida (trabajo grupal con sectores de extrema pobreza), con roles que en otros casos desarrollaban las organizaciones no gubernamentales. Ello fue interrumpido abruptamente por la Dirección Nacional luego de dos años de desarrollo.

En la visión de un exintegrante del CFC de FUCVAM:

"No fue una experiencia muy exitosa, todos los emprendimientos que tienen una función paralela no terminan de resolver la cuestión de vínculo con la estructura de la Dirección de la Federación." (exintegrante del CFC de FUCVAM, citado en Machado, 2017, p. 203).

Esta tensión entre la autonomía que fue asumiendo la gestión de programas sociales y las decisiones políticas de la Dirección Nacional fue resuelta con la finalización de la experiencia.

Es importante destacar que en las áreas de desarrollo de la experiencia no se retomaron las señas de identidad de FUCVAM, sino que se tomaron los procedimientos de las organizaciones no gubernamentales para el trabajo con la población destinataria de los programas, "se trajo una identidad que no es propia, no se aprendió de la propia experiencia de construcción, relaciones más democráticas, la autogestión [...]" (exintegrante del CFC de FUCVAM, citado en Machado, 2017, p. 203).

En el primer período se dieron luchas y enfrentamientos muy importantes de FUCVAM con el Poder Ejecutivo.

A partir del 2008, las conquistas fueron muchas, como la priorización de las líneas de créditos a cooperativas en los Planes Quinquenales 2010-2014 y 2015-2019, la readecuación de las deudas de las cooperativas habitadas, la creación del subsidio a la cuota, la aprobación de una nueva reglamentación que modificó el estudio y la aprobación de los proyectos cooperativos —con la agilización del proceso y la incorporación de sorteos semestrales con cupos para la adjudicación de los préstamos como mecanismo de transparencia- 
y la creación de la Cartera Interinstitucional de Tierras para Viviendas de Interés Social (CIVIS), que prioriza a las cooperativas a nivel nacional.

En 2011 también se destacó el surgimiento del Plan de Vivienda Sindical del PIT-CNT, que generó más de 300 cooperativas de ayuda mutua y de propietarios, utilizando sistemas constructivos no tradicionales. Ese surgimiento enfrentó a FUCVAM con la central sindical, por constituir un movimiento en su interna, en lugar de integrar las nuevas cooperativas a la Federación, como históricamente se ha hecho con los grupos de origen sindical, y, además, por la decisión de constituirse en cooperativas de propietarios.

Este debate fue escasamente abierto, público, lo que seguramente hubiera generado, por un lado, mayor fractura, pero, a su vez, una discusión en torno a las formas de propiedad y la constitución del movimiento popular por el hábitat social.

Actualmente, FUCVAM está enfrentada al Poder Ejecutivo, con una huelga de pagos de las cooperativas de la Reglamentación 2008 en reivindicación de la reducción del interés de los préstamos al porcentaje histórico del $2 \%$. Se ha retomado la Intersocial, formada en la dictadura y posdictadura, ahora junto al PIT-CNT, la Organización Nacional Jubilados y Pensionistas del Uruguay (ONAJPU), la Federación de Estudiantes Universitarios del Uruguay (FEUU), la Intersocial Feminista y otras organizaciones, que muestra su dirección política hacia un bloque popular para enfrentar al nuevo gobierno de coalición, que asumió en marzo de 2020.

\section{Acciones educativas del período}

Este período implicó redefinir el lugar y la posición del movimiento cooperativo con relación a su principal oponente, el gobierno, lo mismo les sucedió al CFC y su propuesta educativa.

Las expectativas generadas con el entonces nuevo gobierno incrementaron el número de cooperativas, a la vez que se inició un proceso cada vez más fluido de obtención de préstamos. Ello reconfiguró la demanda de formación hacia FUCVAM.

Apartir de 2014, la Federación ha desarrollado una nueva institucionalidad para su formación cooperativa, con la creación de la Escuela Nacional de Formación (Enforma), que coloca lo político como eje estructurador de la formación y como respuesta a una suerte de multiplicación de los espacios de formación.

Como fuera señalado, desde 1983 funcionaba el CFC, que mantuvo hasta 2014 cursos regulares para los diferentes roles y procesos de las cooperativas. Por otro lado, el Departamento de Apoyo Técnico, creado para preparar a las cooperativas para la obra y abordar los problemas emergentes de ella, generó ciclos de formación con los objetivos señalados. 
Entre 2011 y 2014 la Dirección Nacional, con apoyos de equipos de Extensión de la UDELAR, promovió cursos y espacios de formación sobre la realidad nacional y los fundamentos políticos del cooperativismo. Se desarmó de esta forma el CFC y se conformó una Secretaría de Formación en la órbita de la Dirección Nacional, que fue la antesala de Enforma.

Además, la colaboración con la Federación de Cooperativas de Vivienda de Usuarios por Ahorro Previo (FECOVI) en la formación sobre gestión de obra muestra cómo el conocimiento sistematizado por FUCVAM a partir de su propia experiencia permite aportar a otras organizaciones, como lo ha hecho con otros países de Latinoamérica. ${ }^{7}$

Actualmente, Enforma desarrolla una grilla estable de cursos de formación sobre gestión cooperativa para los que generó materiales de difusión y otros, en clave de formación política, sobre historia nacional y formación de dirigentes, que se realizan en forma periódica. En el último año ha recuperado debates y prácticas de la educación popular, modificando las metodologías y construyendo nuevas modalidades de formación, tanto centrales como en las cooperativas.

\section{Conclusiones: FUCVAM, entre formar, conformar $\mathrm{y}$ transformar}

En lo reseñado visualizamos que la praxis social tiene carácter pedagógico, distinguiendo acciones con intencionalidad educativa de otras que, sin proponérselo, tienen capacidad de provocar aprendizajes $y$, por tanto, de generar nuevas experiencias e incidir en la transformación de la cosmovisión que portan los sujetos.

Entendemos que los momentos de lucha, confrontación o resistencia se consolidaron como sujetos colectivos en la experiencia de colocar en la esfera pública sus demandas y sus problemas, que no se separaron de sus necesidades ni cuestiones cotidianas, sino que las tramaron en las múltiples determinaciones que las generaron e identificaron oponentes, alternativas y posibles soluciones.

Destacamos la etapa de la dictadura cívico-militar como ese momento de expresión superior de la lucha del movimiento cooperativo, que se alimentó al identificar un enemigo común del campo popular, una forma autoritaria de poder que combatir, que también atacó a las cooperativas en sus posibilidades de crecimiento cualitativo, con el intento de derogar la propiedad colectiva, y cuantitativo, con la supresión de personerías jurídicas y préstamos.

Todo ello fortaleció al movimiento cooperativo, a su unidad, y fue catalizador del descontento popular y las fuerzas militantes que estaban obturadas por la proscripción y el cierre de los sindicatos, movimientos sociales y partidos políticos. 
Fueron momentos que evidenciaron el enraizamiento, como sostiene Weil (Caldart, 2011), de los problemas por los que se lucha, por un lado, con las condiciones políticas, económicas e ideológico-culturales que los generan y, por otro lado, con la historia, en la conformación de sujetos con capacidad de producir cambios en su curso. Esto ha implicado significar los problemas y las demandas en la esfera pública, colocarlos en el campo de lo político — conectados con el derecho y la práctica de habitar-, donde la propiedad colectiva, la ayuda mutua y la autogestión se tornaron políticas en escenarios de confrontación, lucha y disputa ideológica.

Esos momentos fueron los de mayor producción cultural en términos de construcción de una identidad como movimiento, de generación de discurso propio y de recreación de las formas instituidas del cooperativismo en clave política. Estas maneras de instaurar relaciones del presente con el futuro configuran espacios de producción cultural a partir de la proyección de las experiencias en praxis política, en formas organizativas, en nuevas relaciones sociales y en formas novedosas de desplegar sus señas de identidad.

Podemos identificar a las cooperativas — por las formas de propiedad colectiva y la autogestión, que implican el protagonismo de los sujetoscomo prácticas que aumentan la autonomía, que siempre es relativa, como sugiere Williams (1980), con respecto a las formas culturales dominantes.

En los momentos en que se conjugaron las necesidades, las experiencias y utopías — la tríada de León y Zemelman (1997) — fue cuando se dio el mayor anclaje subjetivo en clave contrahegemónica.

En lo que refiere a otros procesos de formación analizados en la revisión bibliográfica, el movimiento cooperativo de vivienda sostuvo una formación que respondió a sus necesidades históricas organizativas y de gestión. Esta formación fue apoyada por equipos técnicos multidisciplinarios que asesoran a las cooperativas, con distintas alianzas y tensiones en la relación con la Federación, por momentos muy conflictivas. En este sentido, es señalable que FUCVAM no promovió ni buscó formar a sus propios técnicos, ni conformar sus propias escuelas o centros de educación formal, como lo hicieron otros movimientos populares en la región.

En Uruguay, por una fuerte presencia del Estado y la validación de la mayor parte de las instituciones, existe una fuerte diferenciación entre la educación formal y la formación política del movimiento, entre la formación técnica y la formación política, como esferas independientes.

Si bien FUCVAM a lo largo de su historia ha variado sus objetivos y modalidades de formación, integrando cursos de gestión y herramientas para el funcionamiento de las cooperativas con otros de carácter más político, de formación de cuadros, hemos observado que la situación y las necesidades concretas de las cooperativas han acarreado la priorización de los vinculados a la gestión cooperativa sobre los políticos. Pero ello no ha inhibido que ambos se transversalicen, de manera tal que la gestión, que implica autogestión y 
protagonismo, se ha politizado y la formación política no se ha desarraigado de la experiencia de construir y habitar.

No obstante, esa transversalización no ha sido siempre sostenida, y fueron los contenidos técnicos y operativos de la gestión los privilegiados en las demandas formativas de las cooperativas, quedando relegados los contenidos ideológicos o políticos, en distintos períodos, a grupos reducidos de militantes.

Otra de las tensiones se dio entre el carácter formativo de la lucha con relación a las otras instancias formativas, y ha enfrentado a dirigentes y técnicos. Esta se ha resuelto separando los ámbitos y segregando los actores. Es decir, la trayectoria de educación cooperativa que integró FUCVAM muestra que las diferencias entre la formación aportada por los técnicos y la de los cooperativistas militantes se han resuelto con la sustitución o el relevo de los primeros, en diferentes momentos de dicha trayectoria.

En este planteo dicotomizado suele no advertirse que la reflexión y la explicitación del proceso organizativo y de movilización refuerzan lo pedagógico, pero también las formas de lucha.

Estas tensiones o nudos han configurado trayectorias educativas con discontinuidades y rupturas que revelan el carácter político de la educación cooperativa.

\section{Referencias bibliográficas}

Abbadie, L.; N. Alonso; L. Bozzo; M. Calone; N. Graña; B. Nahoum; M. Rodríguez Muslera; G. Sarachu; C. Soria; G. Tedros y R. Vallés (2016). Participar o no participar, esa es la cuestión. Dos modelos de producción habitacional y sus resultados. Montevideo: CSIC-UDELAR.

ANV (2020). Informe cooperativas de vivienda. Montevideo: ANV.

Caldart, R. S. (2011). El MST y la formación de los sin tierra: el movimiento social como principio educativo. En Resende-Caldart (2011). Escuela de Ciudadanía. Buenos Aires: Centro Nueva Tierra.

Elisalde, R. y M. Ampudia (coords.) (2009). Movimientos sociales y educación. Buenos Aires: Ediciones Buenos Libros.

Elisalde, R.; N. M. Dal Ri; M. Ampudia; A. Falero y K. Pereira (eds.) (2013). Movimientos sociales, educación popular y trabajo autogestionado en el cono sur. Buenos Aires: Buenos Libros.

FUCVAM (1984). Documento interno XIV Asamblea Nacional de FUCVAM. Hacia un Plan Nacional de Vivienda Popular. Montevideo: FUCVAM. 
FUCVAM (1987). Documento interno del Centro de Formación Cooperativa. Montevideo: FUCVAM.

FUCVAM (1990). Revista Social XX Aniversario. Montevideo: FUCVAM.

FUCVAM (1992). Bases para la discusión del apoyo del CSC a FUCVAM. Montevideo: FUCVAM.

FUCVAM (1995). Revista del XXV Aniversario. Montevideo: FUCVAM.

FUCVAM (2000). Declaración de Principios. Montevideo: FUCVAM.

FUCVAM (s. f.). Sitio web institucional [en línea]. Disponible en: <www. fucvam.org.uy> [acceso: 9 de julio de 2019].

Gentili, P. e I. Sverdlick (2008). Movimientos sociales y derecho a la educación: cuatro estudios. Buenos Aires: Laboratorio de Políticas Públicas.

Gohn, M. G. (1992). Movimentos sociais e educaçao. San Pablo: Cortez Editora. González, G. (2013). Una historia de FUCVAM. Montevideo: Trilce.

Heras Monner Sans, A. I. (2011). En busca de la autonomía. Un análisis sociolingüístico de experiencias asamblearias. Revista Post Convencionales, 3, pp. 103-130.

Imen, P. (2012). Una pedagogía para la solidaridad. Aportes del cooperativismo de crédito. Buenos Aires: Espacio Editorial e Idelcoop.

León, E. y H. Zemelman (coords.) (1997). Subjetividad: umbrales del pensamiento social. Barcelona: Antrophos Editorial Rubí.

Machado, G. (2016). La experiencia de las cooperativas de vivienda en Uruguay. Necesidades, organización e imaginación. Revista Vivienda Popular, 28, pp. 32-39.

Machado, G. (2017). Habitar las experiencias. Aprendizaje y sociabilidad comunitaria en las cooperativas de vivienda en Uruguay [Tesis de Doctorado en Educación]. Paraná: Universidad Nacional de Entre Ríos.

Marx, K. (1962). El 18 de Brumario de Luis Bonaparte. La Habana: Biblioteca del Pueblo.

Menéndez, M. (2014). Educación en movimiento: la experiencia de la Federación Uruguaya de Cooperativas de Vivienda por Ayuda Mutua [Tesis de Maestría en Psicología Social]. Montevideo: Universidad de la República. 
Michi, N. (2010). Movimientos campesinos y educación. El Movimiento de los Trabajadores Rurales Sin Tierra y el Movimiento Campesino de Santiago del Estero-VC. Buenos Aires: El Colectivo.

Michi, N. (2013). Producción de cultura y procesos educativos. Una aproximación a la experiencia del Movimiento Campesino de Santiago del Estero Vía Campesina, Argentina. Revista Educere et educare, 8(15), pp.17-30.

Michi, N.; J. di Matteo y D. Vila (2012). Movimientos populares y procesos formativos. Polifonías. Revista de Educación, 1(1), pp. 22-41.

Midaglia, C. (1992). Las formas de acción colectiva en Uruguay. Montevideo: Trilce.

MVOTMA (s. f.). Programas de compra de vivienda nueva [en línea]. Disponible en: <www.mvotma.gub.uy/tu-vivienda/compra-de-vivienda-nueva> [acceso: 9 de julio de 2019].

Nahoum, B. (comp.) (2008). Una historia con quince mil protagonistas. Las cooperativas de vivienda por ayuda mutua uruguayas. Montevideo: IMJunta de Andalucía.

Nahoum, B. (2013). Algunas claves. Reflexiones sobre aspectos esenciales de las cooperativas de vivienda por ayuda mutua. Montevideo: Trilce.

Ouviña, H. (2012). Educación popular y disputa hegemónica. Los aportes de Antonio Gramsci para el análisis de los proyectos pedagógico-políticos de los movimientos sociales. OSERA, 6, pp. 46-59.

Rebellato, J. L. (1993). Conciencia de clase como proceso. Revista de Trabajo Social, 12, pp. 11-35.

Rebellato, J. L. (2000). Ética de la liberación. Montevideo: EPPAL.

Rebellato, J. L. y L. Giménez (1997). Ética de la autonomía. Los psicólogos en la comunidad. Montevideo: Ed. Roca Viva.

Rodríguez, E. (1985). La juventud como movimiento social. Elementos para el estudio del caso uruguayo. En C. Filgueira (comp.). Movimientos sociales en el Uruguay de hoy. Montevideo: CLACSO-CIESU-Ediciones de la Banda Oriental, pp. 197-225.

Sarachu, G. (2009). Límites y posibilidades de la economía social y solidaria: la recuperación del sentido del trabajo en movimiento. Revista Académica PROCOAS-AUGM, 1(1), pp. 98-105.

Tapia, L. (2008). Politica salvaje. La Paz: CLACSO, Muela del Diablo Editores y Comuna. 
Tapia Uribe, M. (1997). El espacio íntimo en la construcción intersubjetiva. En

E. León y H. Zemelman (coords.). Subjetividad: umbrales del pensamiento social. Barcelona: Antrophos Editorial Rubí, pp. 153-170.

Terra, J. P. (1986). Proceso y significado del cooperativismo uruguayo. Montevideo: Ediciones de la Banda Oriental-Arca.

Thompson, E. P. (1981). A Miseria da Teoría. A um planetaria de erros. San Pablo: Zahar Editores.

Williams, R. (1980). Marxismo y literatura. Barcelona: Península.

Zibechi, R. (1999). La mirada horizontal: movimientos sociales y emancipación. Montevideo: Nordan.

\section{Contribución de autoría}

Este trabajo ha sido realizado en su totalidad por Gustavo Javier Machado Macellaro. 